This article is licensed under the Creative Commons Attribution-NonCommercial 4.0 International License (CC BY-NC) (http://www.karger.com/Services/OpenAccessLicense). Usage and distribution for commercial purposes requires written permission.

\title{
Isolated Bilateral Internal Carotid Artery Stenosis and Recurrent Ischemic Strokes in a Patient with Suspected Giant Cell Arteritis
}

\author{
Clemens Oerding $^{\mathrm{a}} \quad$ Ingmar Kaden $^{\mathrm{b}} \quad$ Kai Wohlfarth ${ }^{\mathrm{a}}$ \\ aDepartment of Neurology, BG-Hospital Bergmannstrost, Halle (Saale), Germany; \\ bepartment of Radiology, BG-Hospital Bergmannstrost, Halle (Saale), Germany
}

\section{Keywords}

Giant cell arteritis · Cranial arteritis · Temporal arteritis · Horton's disease · Vasculitis · Internal carotid artery stenosis $\cdot$ Vessel stenosis $\cdot$ Ischemic stroke $\cdot$ Cerebral revascularization

\begin{abstract}
Giant cell arteritis (GCA) is a common type of vasculitis and may present various forms. Ischemic stroke is one of the complications and sometimes the first symptom of this disease. We want to present the case of a 58-year-old female patient with suspected GCA who suffered from recurrent ischemic strokes due to progressive stenosis of the internal carotid arteries. This site of manifestation is rare but indicative of GCA. The patient was first treated with corticosteroids and methotrexate later with tocilizumab. Facing progressive hemodynamic impairment, an extra-intracranial-bypass-surgery was performed. Although inflammatory activity was reduced, new strokes occurred.

(C) 2019 The Author(s)

Published by S. Karger AG, Basel
\end{abstract}




\section{Case Reports in Neurology}

Case Rep Neurol 2020;12:84-91
\begin{tabular}{ll}
\hline DOI: 10.1159/000504018 & $\begin{array}{l}\text { (c) 2019 The Author(s). Published by S. Karger AG, Basel } \\
\text { www.karger.com/crn }\end{array}$
\end{tabular}

Oerding et al.: Isolated Bilateral Internal Carotid Artery Stenosis and Recurrent Ischemic Strokes in a Patient with Suspected Giant Cell Arteritis

\section{Introduction}

Giant cell arteritis (GCA) is one of the most common types of vasculitis. It primarily affects the aorta and its extracranial branches [1]. Diagnosis can be challenging due to a variable presentation concerning both clinical and radiological findings. Ischemic stroke is a complication of GCA, occurring in about $4-16 \%$ of the patients (partly depending on the conditions under which the strokes were considered GCA-related) [2-6]. Although in most studies, an obligatory inclusion criterion is temporal-artery-biopsy-proven (TAB)-GCA [3, 7] or GCA diagnosis according to ACR criteria (see Table 1), this disease can occur without STA-involvement and new onset headache, scalp tenderness, jaw claudication, or loss of vision $[1,8]$. Thus diagnosis might be delayed. Involvement of other vessels like internal carotid arteries (ICA) or vertebral arteries might cause ischemic strokes as a first symptom of the disease [9]. Vascular imaging can be a helpful instrument particularly in the context of a negative TAB or missing STA involvement. Stenosis or parietal thickening of inflammatory vascular origin, particularly of the carotid or vertebral arteries, seems to play an important role in the occurrence of ischemic strokes, since they can be found in many cases with GCA-related ischemic complications $[9,10]$.

\section{Case Report}

A 58-year-old female patient was admitted to the emergency room complaining of sudden onset palsy of the left arm and leg. The day before, she had had a short transient palsy of the left arm. No headache was present. She had a history of hypertension, hypothyroidism, depression with an onset 2 years prior to the initial hospital admission and a facial nerve palsy around 30 years before. Later, we diagnosed diabetes mellitus type 2 and dyslipidemia. Previous medication included metoprolol, felodipine, duloxetine, and L-thyroxine.

Within the last months before the admission, the patient did not suffer any weight loss, denied night sweats, fever, and headache or other pain.

At the first examination in our emergency room, we saw a left-sided brachyfacial palsy, a positive left Babinski sign but no sensory disturbance or other neurological deficits. Blood pressure was 150/90 $\mathrm{mmHg}$, heart rate $94 \mathrm{bpm}$. Electrocardiogram showed a left axis deviation and sinus rhythm.

CT-angiography and MRI/MR-angiography revealed stenosis of both intracranial ICA pronounced on the right side (Fig. 1), a perfusion deficit of the right hemisphere, and bilateral new infarcts also pronounced on the right side. There was no sign for a dissection. A conventional angiography showed smooth and mostly concentric bilateral distal ICA-stenosis, a 70\% stenosis of the right ICA in the C3-C6 segments and a 60\% stenosis of the left ICA in the same segments.

Laboratory investigation revealed an elevated ESR $(99 \mathrm{~mm} / \mathrm{h}), \mathrm{C}$-reactive protein $(79$ $\mathrm{mg} / \mathrm{L}$ ), and ANA-titer (1:640). A large variety of antibodies found in rheumatic diseases repeatedly tested negative including anti-Sjogren-antibodies A/B, nucleosome-, histone-, Ro-52, RNP-, Mi2- $\alpha / \beta-$, Ku- Centromere A/B-, Sp100-, PML-, Scl-70-, PM-Scl-100/75-, RP-, GP210-, PCNA-, DFS70-, GBM-antibodies, DS-DNA-, cardiolipin-, CCP-, antimitochondrial antibodies, and ANCA (antibodies against myeloperoxidase and proteinase3). CSF was normal. There was 


\section{Case Reports in Neurology}

Case Rep Neurol 2020;12:84-91

DOI: $10.1159 / 000504018$

(C) 2019 The Author(s). Published by S. Karger AG, Basel www.karger.com/crn

Oerding et al.: Isolated Bilateral Internal Carotid Artery Stenosis and Recurrent Ischemic Strokes in a Patient with Suspected Giant Cell Arteritis

a mild anemia (hemoglobin $6.9 \mathrm{mmol} / \mathrm{L}$ ). Testing for HIV and hepatitis B/C was unremarkable. No other cause for ischemic strokes such as atrial fibrillation could be found.

There were no symptoms like tenderness of both STA, painful mouth sores, ulcers, skin-, joint-, genital or eye-involvement. A pathergy test was negative. CSF repeatedly did not show any signs of inflammation. Again, after further testing, there was no proof of a viral or bacterial cause particularly because steroid treatment did not cause any new symptoms or disease progression. Fibromuscular dysplasia was unlikely due to constantly elevated parameters of inflammation and stenoses without "string-of-beads." There were no abnormal vascular networks in the vicinity of the occlusive or stenotic lesions attributable to Moyamoya disease [11]. A whole-body PET-CT in search of a tumor or other inflamed areas was unrevealing however, it was performed while receiving steroid treatment.

Due to missing clinical signs of vasculitis, the patient was dismissed given continuous antiaggregating therapy, a statin, metformin, and sent to neurorehabilitation. A follow-up visit 6 months later was arranged.

Although during that next hospital stay the patient did not complain of any new symptoms, MRI showed new infarcts on the right side and an occlusion of the right ICA (Fig. 2). Again, no headache was reported; duplex-sonography did not show halo sign or stenosis of either STA (superficial temporal artery). Inflammatory parameters were still elevated (ESR $112 \mathrm{~mm} / \mathrm{h}$, CRP $105 \mathrm{mg} / \mathrm{L}$ ). A temporal artery biopsy (TAB) on the right side including brain parenchyma and dura mater biopsy was performed showing no results of inflammation. A biopsy of the stenotic or occluded carotid artery region was not feasible. Suspecting CGA and facing progressive ischemic strokes and vessel stenoses, we decided to start a steroid treatment under which blood sedimentation rate and CRP decreased.

At that time, no contrast-enhanced MRI was available. Nine months after the first hospital admission and still under corticoid treatment, an MR-angiography ("black-blood imaging sequence") revealed left-sided ICA vessel wall enhancement of the cavernous and petrosal segments (Fig. 3) which can be considered a proof of CGA in that context.

Several months later, the patient was emergently presented to our hospital because of new sensorimotor disturbances on the right side. We decided to discuss this case with our neurosurgery colleagues who performed an extra-intracranial bypass surgery due to severe hemodynamic impairment of both hemispheres at which a radial artery autograft was inserted between a medial cerebral artery branch and the external carotid artery close to the carotid bulb.

Following several months of neurorehabilitation, the patient received treatment with methotrexate and corticosteroids. Several months later, after trying to reduce the dose of corticosteroids, the patient was presented again to the emergency room two different times with new bilateral frontal infarcts and now bilateral ICA occlusions. A duplex sonography still showed a large contribution of the bypass to the left hemisphere's perfusion. The right hemisphere is predominantly supplied by the posterior circulation. We began a medication with tocilizumab. However, partly attributable to a hemodynamic mechanism new strokes occurred. To date, the patient has e palsy of the left arm, neurocognitive disturbances, and needs nursing care. 


\section{Case Reports in Neurology}

\begin{tabular}{l|l}
\hline Case Rep Neurol 2020;12:84-91 \\
\hline DOI: 10.1159/000504018 & $\begin{array}{l}\text { (c) 2019 The Author(s). Published by S. Karger AG, Basel } \\
\text { www.karger.com/crn }\end{array}$
\end{tabular}

Oerding et al.: Isolated Bilateral Internal Carotid Artery Stenosis and Recurrent Ischemic Strokes in a Patient with Suspected Giant Cell Arteritis

\section{Discussion}

We present a patient with GCA and rapidly progressive vessel stenoses despite intensive immunosuppressive therapy plateauing in occlusion of both ICA which led to strokes and hemodynamic impairment.

Although ICA-involvement has been reported before as a rare but characteristic pattern in GCA, especially in the petrous and cavernous segments $[12,13]$, to our knowledge this is the first reported case of a patient with GCA, recurrent bihemispheric strokes, and no other vessel involvement than both intracranial/extradural ICA. Our literature research did not provide comparable cases regarding the location of stenosis and occurrence of ischemic strokes in other categories of vasculitis (Takayasu arteritis, polyarteritis nodosa, ANCA-associated small vessel vasculitis, PACNS, etc.).

It seems that involvement of carotid and vertebral arteries adds to the risk of ischemic strokes in GCA $[9,10]$. We did not find data proving that the degree of inflammatory vascular stenosis influences the amount and severity of ischemic strokes by mechanisms beyond hemodynamics.

We concur with previous findings that this unusual manifestation of GCA only in the ICA caused a lower chance of developing headache or jaw claudication [14] and is a reason why our patient could not be diagnosed according to ACR-criteria (Table 1), since initially only elevated ESR and age $>50$ years were present. Even more proper imaging (MRI e.g., black-blood imaging sequence or PET-CT) is needed to search for vasculitis in the case of clinically suspected GCA in order to initiate early immunosuppressive therapy.

Another particularity of this case is the combined pharmaceutical and surgical treatment with an extra-intracranial bypass. There are previous cases in which patients with GCA and distal ICA occlusions received an STA-MCA bypass [15] or bypass plus EMS [16]. To our knowledge, this is the first case with a successfully performed high-flow autograft-extra/intracranial bypass in a patient with GCA. Performance of this procedure is an invasive but beneficial option for a well selected group of patients that face progressive hemodynamic impairment and ischemic strokes.

Along with our case in previous studies, diabetes, arterial hypertension, and hyperlipidemia were more common in GCA patients developing stenosis rather than in GCA patients without stenosis $[6,7]$ thus atherosclerosis might contribute to the mechanisms causing ischemic strokes in GCA patients. An emphasized treatment of these risk factors should be considered equally as important as in patients with ischemic strokes of sole atherosclerotic origin.

In a large observational cohort study, the risk of an ischemic stroke was nearly 5 times higher in the first month after the diagnosis of CGA compared to control data base patients and only $27 \%$ higher in a total follow-up period of several years (median follow-up time 3.9 years) [4] which is probably attributable to medical treatment. These findings might possibly be applicable to GCA flares where similar discoveries were made [9]. In our present case, this link was also to be assumed, since new ischemic strokes occurred after reducing the dose of corticosteroids. 


\section{Conclusion}

Our aim is to depict the challenges of diagnosing a common but variously presenting disease following established criteria. It is self-evident that there are exceptional clinical courses of GCA differing from the 'classic' ones in terms of key signs and symptoms which necessitates a wide and careful search for other diseases explaining the symptoms. A comparison with similar cases can provide a clue to find the right diagnosis. Eventually an early diagnosis of this disease is beneficial for the patient, since by starting immunotherapy, complications like ischemic strokes can potentially be avoided.

\section{Acknowledgement}

We would like to thank our patient for generously providing us with her time. Also, we would like to thank Frank Uhlmann, Johannes Wollmann, Thiemo Fiedler, Beate Betram, and Olaf Niederstrasser for their contribution in terms of diagnostics and treatment.

\section{Statement of Ethics}

The patient provided written informed consent for the publication of this case report.

\section{Disclosure Statement}

The authors have no conflicts of interest to declare.

\section{Funding Sources}

The authors received no funding support for the publication of this case report.

\section{References}

1 Gonzalez-Gay MA, Vazquez-Rodriguez TR, Lopez-Diaz MJ, Miranda-Filloy JA, Gonzalez-Juanatey C, Martin J, et al. Epidemiology of giant cell arteritis and polymyalgia rheumatica. Arthritis Rheum. 2009 Oct;61(10):1454-61.

2 Zenone T, Puget M. Characteristics of cerebrovascular accidents at time of diagnosis in a series of 98 patients with giant cell arteritis. Rheumatol Int. 2013 Dec;33(12):3017-23.

3 Samson M, Jacquin A, Audia S, Daubail B, Devilliers H, Petrella T, et al. Stroke associated with giant cell arteritis: a population-based study. J Neurol Neurosurg Psychiatry. 2015 Feb;86(2):216-21.

4 Tomasson G, Peloquin C, Mohammad A, Love TJ, Zhang Y, Choi HK, et al. Risk for cardiovascular disease early and late after a diagnosis of giant-cell arteritis: a cohort study. Ann Intern Med. 2014 Jan;160(2):73-80.

5 Caselli RJ, Hunder GG. Neurologic complications of giant cell (temporal) arteritis. Semin Neurol. 1994 Dec;14(4):349-53.

6 Pariente A, Guédon A, Alamowitch S, Thietart S, Carrat F, Delorme S, et al. Ischemic stroke in giant-cell arteritis: French retrospective study. J Autoimmun. 2019 May;99:48-51. 
Oerding et al.: Isolated Bilateral Internal Carotid Artery Stenosis and Recurrent Ischemic Strokes in a Patient with Suspected Giant Cell Arteritis

7 Salvarani C, Della Bella C, Cimino L, Macchioni P, Formisano D, Bajocchi G, et al. Risk factors for severe cranial ischaemic events in an Italian population-based cohort of patients with giant cell arteritis. Rheumatology (Oxford). 2009 Mar;48(3):250-3.

8 de Boysson H, Lambert M, Liozon E, Boutemy J, Maigné G, Ollivier Y, et al. Giant-cell arteritis without cranial manifestations: working diagnosis of a distinct disease pattern. Medicine (Baltimore). 2016 Jun;95(26):e3818.

9 Chazal T, Couture P, Rosso C, Haroche J, Léger A, Hervier B, et al. Cerebrovascular events are associated with lower survival in giant cell arteritis: A case-controlled multicenter study. Joint Bone Spine. 2018 May;85(3):383-5.

10 Larivière D, Sacre K, Klein I, Hyafil F, Choudat L, Chauveheid MP, et al. Extra- and intracranial cerebral vasculitis in giant cell arteritis: an observational study. Medicine (Baltimore). 2014 Dec;93(28):e265.

11 Hishikawa T, Sugiu K, Date I. Moyamoya Disease: A Review of Clinical Research. Acta Med Okayama. 2016 Aug;70(4):229-36.

12 Bogousslavsky J, Deruaz JP, Regli F. Bilateral obstruction of internal carotid artery from giant-cell arteritis and massive infarction limited to the vertebrobasilar area. Eur Neurol. 1985;24(1):57-61.

13 Wilkinson IM, Russell RW. Arteries of the head and neck in giant cell arteritis. A pathological study to show the pattern of arterial involvement. Arch Neurol. 1972 Nov;27(5):378-91.

14 Koster MJ, Matteson EL, Warrington KJ. Large-vessel giant cell arteritis: diagnosis, monitoring and management. Rheumatology (Oxford). 2018 Feb;57 suppl_2:ii32-42.

15 Abiko M, Nakano S, Nishizaki T, Ikeda N, Sakakura T, Okamura T, et al. [Superficial temporal artery-middle cerebral artery anastomosis in a patient of temporal arteritis with internal carotid artery occlusion: a case report]. No Shinkei Geka. 2012 Jan;40(1):43-8. Japanase.

16 Chowdhary V, Kallmes DF, Fulgham J, Meyer F, Matteson EL. Recurrent spells and bilateral internal carotid artery stenosis in a diabetic male: a test of patien-ce(-ts). Arthritis Rheum. 2007 Aug;57(6):1098-101.
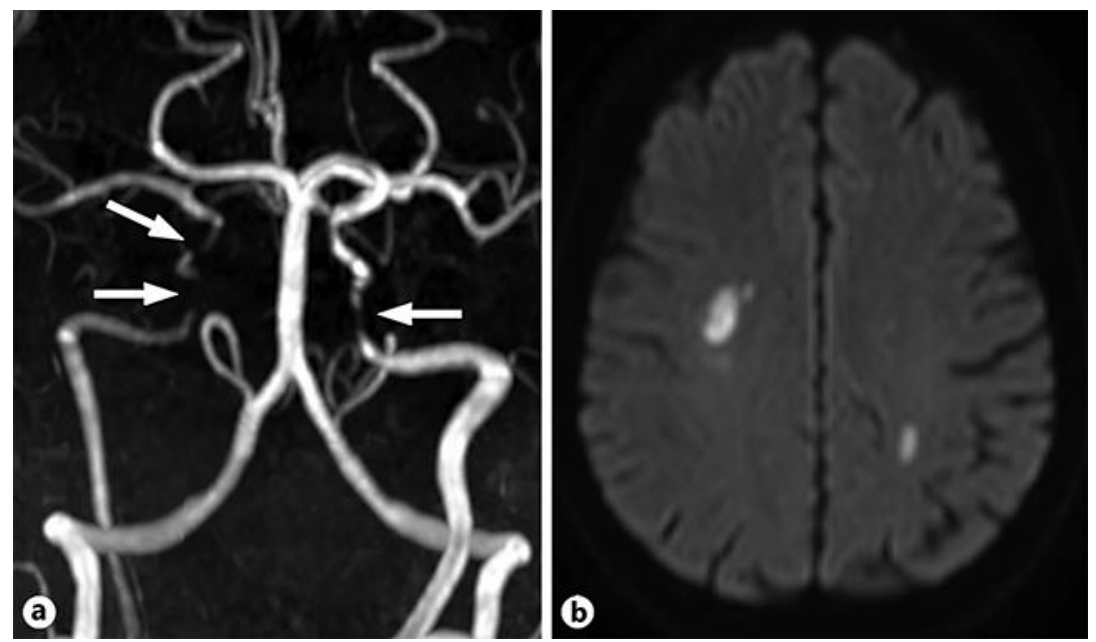

Fig. 1. MRI performed at the beginning of the first hospital admission showing bilateral hemispheric infarction (a) in DWI and a time of flight imaging (b) revealing bilateral ICA-stenosis including the right C3C5 segments and the left C3-C4 segments (see arrows, classification according to Bouthillier 1996). 


\section{Case Reports in Neurology}

\begin{tabular}{l|l} 
Case Rep Neurol 2020;12:84-91 \\
\hline DOI: 10.1159/000504018 & $\begin{array}{l}\text { (C) 2019 The Author(s). Published by S. Karger AG, Basel } \\
\text { www.karger.com/crn }\end{array}$ \\
\hline
\end{tabular}

Oerding et al.: Isolated Bilateral Internal Carotid Artery Stenosis and Recurrent Ischemic Strokes in a Patient with Suspected Giant Cell Arteritis
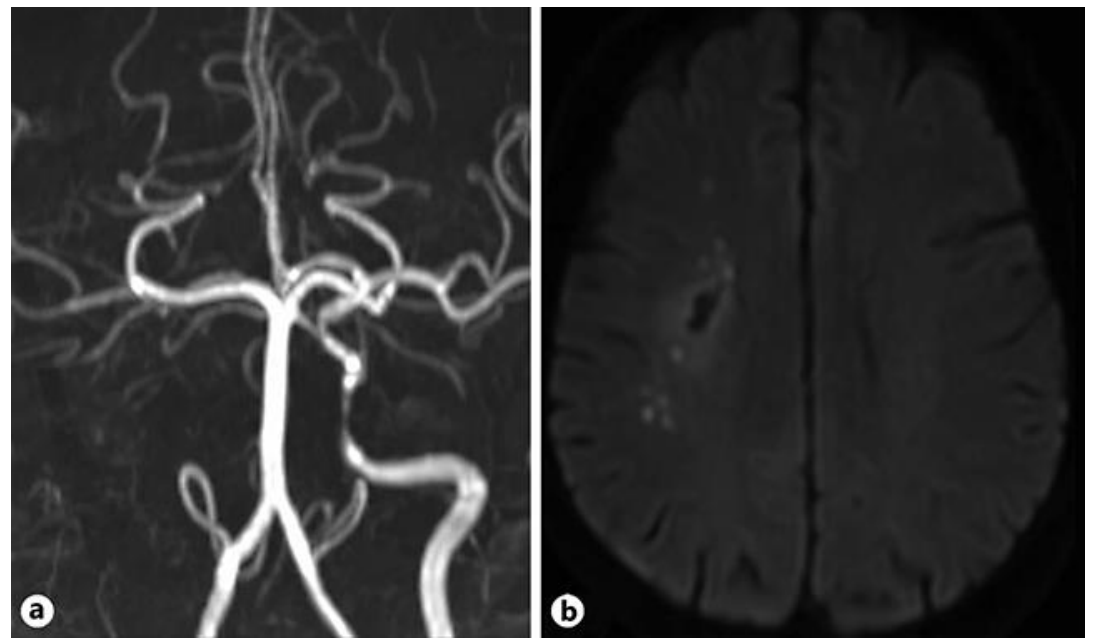

Fig. 2. MRI performed 4 months after the initial hospital admission showing a new ICA occlusion on the right side and an ICA stenosis on the left side nearly identical to the previous imaging (see arrows, C3-C4 segments).
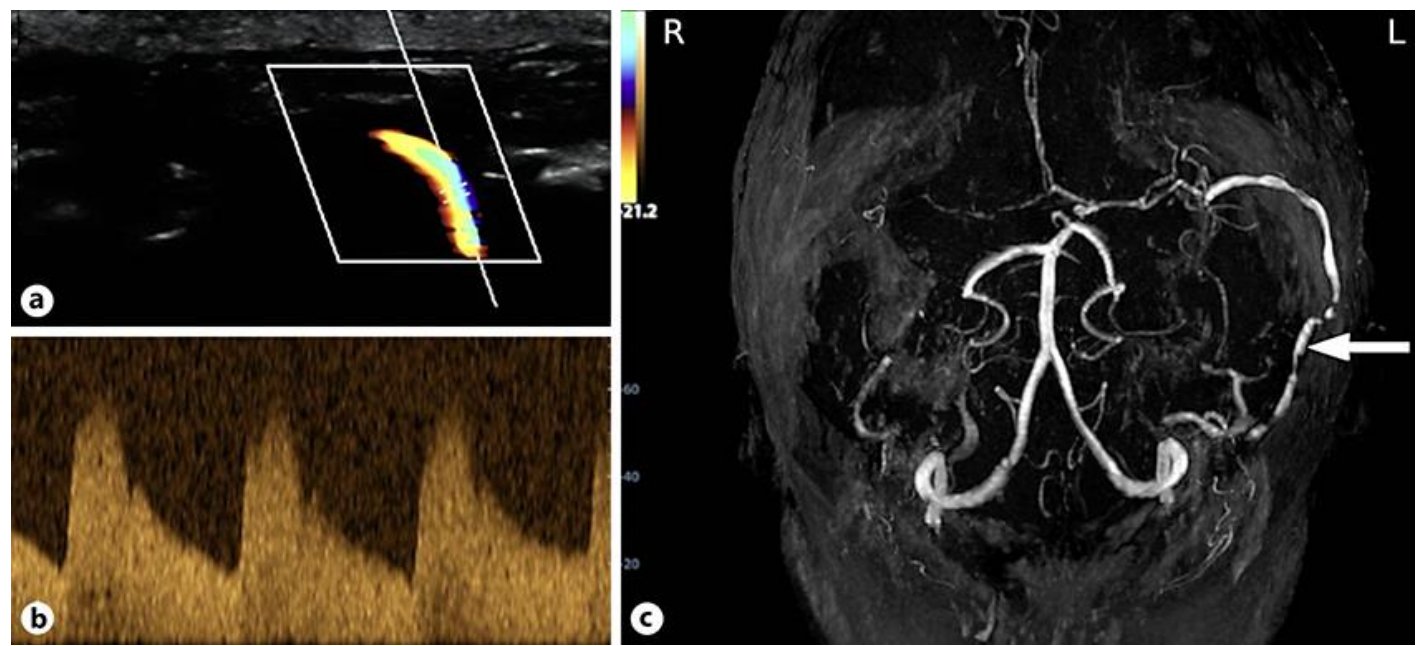

Fig. 3. Duplex sonography (a), PW-Doppler image (b), and MRI time of flight imaging (c) of the left sided extra-intracranial bypass. 
Table 1. The American college of rheumatology 1990 GCA classification criteria

Patients must fulfill 3 of the following 5 criteria

\begin{tabular}{ll}
\hline Criterion & Definition \\
\hline 1 Age at onset $\geq 50$ years & $\begin{array}{l}\text { Development of symptoms or findings beginning at age } 50 \text { years } \\
\text { or older }\end{array}$ \\
\hline 2 New headache & New onset or new type of localized pain in the head \\
\hline 3 Temporal artery abnormality & $\begin{array}{l}\text { Temporal artery tenderness to palpitation or decreased pulsation, } \\
\text { unrelated to arteriosclerosis of cervical arteries }\end{array}$ \\
\hline 4 Erythrocyte sedimentation rate & $\begin{array}{l}\text { Erythrocyte sedimentation rate } \geq 50 \text { mm/h by the Westergren } \\
\text { method }\end{array}$ \\
\hline 5 Abnormal artery biopsy & $\begin{array}{l}\text { Biopsy specimen with artery showing vasculitis characterized by a } \\
\text { predominance of mononuclear cell infiltration or granulomatous } \\
\text { inflammation usually with multinucleated giant cells }\end{array}$ \\
\hline
\end{tabular}

